\title{
REFORMA RELIGIOSA Y CONSTITUCIONALISMO. UNA CLASE DE DERECHO CONSTITUCIONAL A TRAVES DEL MONUMENTO INTERNACIONAL DE LA REFORMA DE GINEBRA
}

\author{
Eduardo J. Ruiz Vieytez \\ Universidad de Deusto
}

\begin{abstract}
Sumario: 1. Introducción: religión y política en la historia europea. 2. El Muro de los Reformadores. 3. Los acontecimientos históricos y su relevancia constitucional. 4. Las bases del constitucionalismo moderno. 5. Conclusión. 6. Bibliografía.
\end{abstract}

\section{Introducción: religión y política en la historia europea}

Dibujar literariamente los grandes trazos de las relaciones entre religión y política es una labor tan arriesgada como sugerente. Sin embargo, la influencia recíproca que ambas esferas han ejercido en la historia europea muy difícilmente puede ponerse en duda. Esta influencia se plasma básicamente desde la religión a la política, máxime si la perspectiva de aproximación es la del estudio del constitucionalismo. En todo caso, nuestra herencia jurídico-política moderna ha necesitado fundamentarse en concepciones que deben mucho a la religión o a la estructuración de la misma, cuando no apoyarse en ella directamente. La separación entre poder espiritual y temporal, de hecho, no deja de ser un elemento muy reciente de la historia europea que, incluso aún en varios países de nuestro continente no ha llegado a consumarse definitivamente.

El Cristianismo es desde luego la religión que preside la evolución política europea prácticamente desde el siglo IV, si bien no puede olvidarse el influjo que otras experiencias religiosas como el judaísmo o el Islam han podido proyectar en la misma, particularmente en determinados ámbitos geográficos. Sin embargo, a nuestros efectos, cabe también distinguir entre unos y otros cristianismos y, más concretamente, entre unas y otras iglesias cristianas, puesto que la organización eclesiástica respectiva ha sido tradicionalmente no sólo reflejo de concepciones organizativas del poder, sino también inspiración y modelo de las mismas.

Si bien el Cristianismo originario parece ofrecer una visión del mundo en la que se propugna la separación del actuar político respecto de la experiencia religiosa, la adopción del mismo por el Imperio romano como religión prácticamente oficial a partir del siglo IV y la consi- 
guiente adaptación eclesiástica realizada en el primer concilio ecuménico de Nicea (325) supone la identificación sucesiva entre culto cristiano e Imperio. Este es el primer cambio cualitativo de la historia política de la religión cristiana. La Iglesia se sumerge entonces en una simbiosis con la organización política dominante, que se traducirá en una dependencia recíproca no sólo material sino también espiritual y que acompañará tanto al ámbito europeo occidental como al oriental hasta la Edad moderna, época en la que desaparece definitivamente el Imperio de Oriente, mientras en Occidente adquiere fortuna variada el movimiento conocido como Reforma. Aún más, el proceso de progresiva cristianización del continente puede ser interpretado como una continuación en clave cultural de la romanización, incluso para las épocas en las que el Imperio de Occidente ya había dejado de existir.

En el mismo período en el que se opera la simbiosis con el poder político temporal, se produce el definitivo impulso del monacato, que sería la expresión reformadora más importante en el seno de las iglesias cristianas durante los primeros catorce siglos (Meyendorff, 13). En efecto, el monacato, tanto en su expresión original eremítica como cenobítica (Parry, 230), ha supuesto durante siglos el intento por recuperar una Iglesia cristiana más adecuada a los tiempos iniciales, una visión más austera y desvinculada de los fenómenos temporales y, en definitiva, una aportación del original orientalismo cristiano. La vivencia de este fenómeno reformador fue paulatinamente diferenciándose entre occidente y oriente a medida que la historia política y la evolución social de ambas esferas culturales iban igualmente divergiendo.

Del mismo modo, los substratos culturales iban marcando diferencias religiosas y políticas que se retroalimentarían progresivamente. A partir de la desaparición del Imperio romano en occidente, las realidades políticas y religiosas empezaron a diferenciarse. La Iglesia occidental, incuestionablemente liderada por el patriarcado romano, tuvo que vivir adaptada a una pluralidad cambiante de espacios políticos y reforzó una centralidad y un grado de independencia que se hacían necesarios para su propio mantenimiento. Por el contrario, en Oriente la Iglesia se encontró demasiado vinculada a un poder temporal que de hecho en gran parte la controlaba. A ello debe añadirse la pluralidad patriarcal de oriente y, desde luego, una tradición helenística dominante muy vinculada a la especulación filosófica y teológica. Las divisiones políticas y religiosas fueron de la mano, no ya sólo respecto a los cristianos que quedaban fuera del ámbito imperial, como los armenios y la mayor parte de los nestorianos, sino también para aquéllos que vivían sometidos a Constantinopla. Así se consumó en el Concilio de Calcedonia (451) la escisión monofisita, especialmente en los patriar- 
cados de Antioquía y Alejandría, que llevó a la constitución de más iglesias paralelas nacionales y con el tiempo a la fácil islamización de los territorios sometidos a dichas sedes. Por otro lado, la expansión misionera bizantina hacia los pueblos eslavos, se hizo utilizando una nueva lengua litúrgica e incluso un nuevo alfabeto. En definitiva, en la esfera oriental todo apuntaba ya desde los comienzos de la Edad Media a una nacionalización o al menos compartimentalización del fenómeno religioso que lo haría más dependiente del poder político, pero al tiempo menos rígido y jerárquico que la Iglesia occidental.

Todas estas divisiones que se operan en el seno de una cristiandad que en teoría es o debiera ser única, influyeron desde luego en la formulación de las teorías políticas. Occidente consiguió mantener su unidad religiosa, aunque no sin dificultades. Durante buena parte de la Edad Media se discute sobre la primacía temporal de Imperio o Papado, al tiempo que cíclicamente se producirían movimientos de reforma en el propio seno de la Iglesia (Mitre, 59). Algunos de ellos serían eliminados como heréticos, pero otros se consolidan en una Iglesia que, a diferencia de la bizantina, admite pluralidad de jurisdicciones en su interior. A finales de este período es cuando llega a su punto culminante la discusión sobre la autoridad suprema de la Iglesia entre Papa y Concilio y la tensión acumulada durante siglos se romperá de modo brusco sólo cuando las monarquías nacionales están en un proceso imparable de consolidación y ceda de modo irreversible en la práctica la pretendida universalidad gubernativa del Imperio y del Papado. Será entonces cuando un movimiento complejo como la Reforma pueda tener un éxito que le hará desarrollar nuevas teorías eclesiásticas y políticas. Será en todo caso un movimiento apoyado en el poder político y que, en consecuencia, produzca nuevas legitimaciones y deslegitimaciones del mismo y que de lugar a acontecimientos que marcarán importantes consecuencias para nuestra evolución política posterior (Touchard, 214).

En Oriente, donde no se ha desarrollado una tendencia paralela a la escolástica y permanece poco alterada la nula diferenciación de saberes que se imponía por una visión teológica tradicional, la conquista otomana ayuda a bloquear otra suerte de desarrollos. Los Otomanos convierten al Patriarcado de Constantinopla en un importante foco de poder religioso y político sobre el conjunto de poblaciones cristianas sometidas a la Sublime Puerta, perpetuándose la dependencia de esta Iglesia respecto al poder temporal establecido. Esta tendencia no será alterada hasta el siglo XIX, con el despertar del nacionalismo y la intervención imperialista de potencias extranjeras. En ese momento, las iglesias orientales ortodoxas volverán a experimentar un proceso de división sobre la base de las diferencias nacionales que conducirá a la 
situación de sometimiento al Estado respectivo que ha caracterizado la evolución de estas comunidades cristianas en el siglo XX.

En Occidente, puede decirse que tanto el nacionalismo como determinadas concepciones constitucionales se adelantan en parte gracias a la reforma religiosa del siglo XVI (Hernández, 215). El luteranismo y, sobre todo, el calvinismo van a dar lugar al desarrollo de ideas constitucionales e incluso protodemocráticas. Ello no se deberá, desde luego, a la ideología de los inspiradores de dichas corrientes reformadoras, sino principalmente a las circunstancias en las que las mismas se propagarán (Johnston, 160).

En efecto, entre los grandes temas que se suscitarán por o junto con la Reforma y que provocarán la aparición de nuevas teorías políticas, se encuentran el del tratamiento de la diferencia tanto religiosa como étnica, la apuesta por la formación literaria, la confianza moderna en la capacidad de aprendizaje y crítica del ser individual, el cuestionamiento de la resistencia frente al poder político establecido o la aceptación del subjetivismo. Al tiempo, el Estado se va consolidando como la única forma política viable que es capaz de garantizar el orden y, en su caso, los derechos de la Iglesia o de los creyentes.

Todos los factores que concurren irán poniendo las bases necesarias para legitimar el reconocimiento de derechos de los individuos y la limitación del poder político. La Reforma ayudará en términos generales a la lucha contra el absolutismo y a medio plazo a los primeros éxitos del constitucionalismo. Aunque en la aparición y desarrollo de éste concurren otras muchas fuerzas intelectuales y materiales, la Reforma va ligada de modo inevitable a la modernización de las sociedades europeo-occidentales, que en términos políticos se traducirá más adelante en constitucionalismo. La Europa oriental, sin embargo, ha debido recibir este influjo desde el occidente, dado que las circunstancias políticas y religiosas no permitieron desarrollar una teoría política propia en clave moderna. Sin embargo, sería precisamente en ese espacio geográfico en el que la libertad personal no había tenido tiempo de consolidarse religiosa y políticamente, donde triunfarían las revoluciones de inspiración marxista. La diferente asunción del socialismo revolucionario en una y otra parte del continente puede, por consiguiente, no sólo responder a las circunstancias que han operado en uno y otro ámbito, sino también a consideraciones más profundas que forman lo que denominamos habitualmente cultura política o cultura profunda de los pueblos o de las civilizaciones ${ }^{1}$.

1 Sobre las culturas profundas, vid. Galtung, J. (2003), Paz por medios pacíficos. Paz y conflicto, desarrollo y civilización, Bakeaz - Gernika Gogoratuz, Gernika. 


\section{El Muro de los Reformadores}

El Monumento Internacional de la Reforma, más conocido como Muro de los Reformadores, situado en el Parque de los Bastiones de Ginebra (Suiza), fue construido entre 1909 y 1917 para conmemorar el 400 aniversario del nacimiento de Juan Calvino y el 350 aniversario de la fundación de la Academia ginebrina en 1559. Se trata de una solemne pared que forma parte de las defensas iniciales de la villa, austeramente esculpida alternando bajorrelieves y estatuas. El monumento, que ofrece una disposición casi simétrica, fue concebido por los arquitectos de Lausana Alphonse Laverrière y Jean Taillens y ejecutado por los escultores parisinos Henri Bouchard y Paul Landowski. La construcción del Monumento fue financiada a través de una suscripción popular a la que contribuyeron mayormente fieles protestantes de diversos países europeos y americanos, perteneciendo actualmente a la villa de Ginebra (Higman, 3).

El Monumento está presidido por un grupo central de 4 figuras, cada una de ellas de hasta 5 metros de altura, que representan a Jean Calvino, John Knox, Teodoro de Bèze y Guillermo Farel, es decir, los cuatro grandes reformadores presentes en Ginebra en el año 1559. Esta fecha es precisamente la que figura esculpida en los dos extremos laterales de este grupo central, junto a leyendas que recuerdan cuatro acontecimientos relevantes para la causa calvinista: la mencionada fundación de la universidad ginebrina, la firma del covenant de Perth, la primera predicación de la reforma en Edimburgo y la primera reunión del sínodo general de París. En los dos extremos del conjunto figuran igualmente conmemoraciones de acontecimientos señalados en la vida de la ciudad. Por una parte, la adopción en 1556 por parte del Consejo General de Ginebra de los edictos de reforma de su iglesia y el decreto relativo a la instrucción obligatoria. Por otro lado, la exitosa autodefensa de la villa frente al ataque del Duque de Saboya en 1602, victoria que permitió a Ginebra mantener su independencia política y religiosa hasta que, tras el paréntesis napoleónico, en virtud del congreso de Viena, fuera unida a la Confederación Suiza como un cantón más de la misma. Los nombres de Lutero y Zwinglio, así como los escudos de Ginebra, Berna y Escocia también adornan el conjunto, que está presidido por el lema de Ginebra y de su Reforma: Post Tenebras Lux.

Desde un punto de vista político, sin embargo, los elementos más relevantes se encuentran situados en los relieves de las dos alas del monumento. Los relieves conmemoran acontecimientos resaltados en la historia temprana de la Reforma, especialmente ligados al principio de tolerancia religiosa y, en consecuencia, a conceptos tan relevantes para 
el Derecho constitucional como los derechos de los individuos y la limitación del poder. En cada ala figuran cuatro relieves con sendas inscripciones en francés, neerlandés, alemán, inglés y latín. Uno de los muchos méritos del monumento como instrumento pedagógico es, precisamente, el haber incorporado las inscripciones relevantes en el idioma original correspondiente, lo cual demuestra también su vocación internacional. Los cuatro relieves de cada ala del Muro se hallan separados por estatuas de menor tamaño que las del grupo central, y que representan a personajes tan históricamente señalados como el francés Gaspard de Coligny (1517-1572), el holandés Guillermo el Taciturno (1533-1584), el prusiano Federico Guillermo de Brandenburgo (1620-1688), los ingleses Roger Williams (1604-1683) y Oliver Cromwell (1599-1658) y el húngaro Estéfano Bocskay (1556-1606).

El análisis del papel desempeñado por estos personajes históricos, unido a la significación política de varios de los acontecimientos celebrados en el monumento es lo que nos permite realizar un interesante paseo histórico con el que comprender mejor el surgimiento de alguno de los principios básicos del Derecho constitucional moderno, así como la relación que existe entre determinadas diferencias religiosas y las ideas políticas que triunfarían en la modernidad.

\section{Los acontecimientos históricos y su relevancia constitucional}

Los ocho acontecimientos que aparecen conmemorados en el Muro corresponden a eventos de base mayor o menormente religiosa de la historia de Suiza, Hungría, Prusia, Inglaterra, Escocia, Francia, Países Bajos y Estados Unidos. Todos ellos se hallan ubicados temporalmente en la Edad Moderna, entre los siglos XVI y XVII, período en el cual se ponen las bases ideológicas y, en parte fácticas, del futuro constitucionalismo moderno. Los hechos reflejados en el monumento, ordenados cronológicamente, son los siguientes:

a) 22 de febrero de 1534: Celebración del primer bautismo evangélico en Ginebra. El acontecimiento aparece en primera instancia como básicamente religioso, pero no deja de presentar elementos políticos de honda significación para la posterior tradición constitucional suiza. En efecto, como señala el propio relieve, la Reforma es predicada en Ginebra «en presencia de los enviados de Berna». La primera mitad del siglo XVI asiste a una división religiosa en el seno de la Confederación Helvética que plasma dos formas de entender no sólo la Iglesia sino la 
propia sociedad. Los cantones rurales se alinean con Roma, mientras los cantones de ambiente más urbano, en los que el humanismo ha tenido más campo de irradiación, apoyarían diversas vías de Reforma. Es el caso de Zurich, de Basilea o de Berna. El apoyo de esta última ciudad y de su poderoso ejército permite a Ginebra consolidar su Reforma, no sólo como un movimiento de renovación religiosa sino también como una afirmación de su independencia respecto del duque de Saboya y del propio Obispo de la ciudad. Ginebra tardaría aún mucho tiempo en incorporarse a la Confederación (no lo haría hasta 1815), pero a partir de la Reforma orientaría sus miras a ese espacio político diferenciado que formaría Suiza. Igualmente relevante es la participación directa del pueblo en la adopción de la reforma ginebrina, también reflejada en el relieve. Esta participación activa de la población está en la base de una concepción teóricamente más democrática de Iglesia (aunque con Calvino derivaría en una auténtica Teocracia), que a su vez servirá de substrato para las teorías políticas de Rousseau y para el desarrollo de los mecanismos de democracia directa, tan profusamente utilizados en el constitucionalismo suizo actual.

b) Agosto de 1565: John Knox predica la Reforma en la Catedral de Saint Giles, Edimburgo, delante de la Corte de María Estuardo. Escocia sería el primer país en adoptar oficialmente la reforma religiosa de inspiración calvinista en 1572. Ello iría precedido de un período convulso en la historia política de este país, que se debatía entre dos influencias políticas contrapuestas, una capitaneada por la vecina Inglaterra y la otra por la potencia continental francesa. Pronto estas divisiones tuvieron un trasfondo religioso, especialmente aprovechando la minoría de edad de la soberana. En diciembre de 1557, un sector de notables escoceses, agrupados bajo el título de «Lores de la Congregación», se constituyeron en una Liga o Covenant con el declarado propósito de defender la Palabra de Dios. Tras la derrota de las tropas francesas por el apoyo inglés, el Parlamento escocés repudiará la autoridad de Roma y comenzaría un paulatino proceso que llevaría al establecimiento de la Iglesia presbiteriana escocesa. Durante el tiempo que duraría aún la independencia escocesa, la historia eclesiástica de Escocia es la historia del intento por crear o rechazar un sistema de presbiterios independientes y soberanos. Se trata de un proceso de consolidación eclesiástica que refleja en cierto modo la paralela lucha constitucional (Sabine, 289). Mientras la corona y el gobierno fueron 
débiles, los presbiterios obtuvieron fuerza legal e independencia política. En los momentos en los que el gobierno era fuerte, los derechos reclamados por los presbiterios fueron derogados o disminuidos (Chadwick, 172).

c) 26 de julio de 1581: Los Estados Generales adoptan en La Haya la Declaración de Independencia de las Provincias Unidas. Esta Declaración, evidentemente ligada al proceso de reforma religiosa de los Países Bajos del norte, tiene fundamentalmente importancia política y puede considerarse como uno de los sucesos más relevantes de la historia europea moderna. La importancia del hecho deriva, por una parte, de la formación de una nueva comunidad política a través de la legitimación de una secesión unilateral, lo que serviría de referencia para la posterior independencia norteamericana. El hecho plantea, desde luego, la discusión sobre la creación o mantenimiento de las formas políticas como espacios de decisión y legitimación. Por otro lado, y en íntima conexión con la legitimación de la secesión, en la Declaración neerlandesa se encuentra el principio en virtud del cual el poder político está orientado al bien de los gobernados. En el mismo sustrato ideológico se esconde la justificación del derecho de resistencia, cuya legitimación plantearon en el mismo siglo XVI no sólo pensadores de inspiración calvinista, sino también varios jesuitas activos en la Contrarreforma (Touchard, 225). Derecho de resistencia y derecho a la secesión caminan, por tanto, de la mano en el proceso de legitimación de las ideas políticas contemporáneas. La declaración aquí aludida es no sólo el precedente de la Declaración de independencia norteamericana, sino también de la Declaración de Derechos inglesa de 1689.

d) 13 de abril de 1598: Enrique III de Navarra, IV de Francia, firma el Edicto de Nantes. Las guerras de religión desarrolladas a lo largo de casi todo el siglo XVI suponen un aldabonazo importante en la consolidación de la monarquía francesa. De su resolución, Francia y su institución real saldrán políticamente reforzadas para liderar el ámbito geopolítico europeo durante prácticamente dos siglos. La guerras de religión son precisamente el marco que impulsa a Bodino a desarrollar sus teorías de la tolerancia y a poner indirectamente las bases del posterior absolutismo (Sabine, 313). La división de las familias notables en dos bandos enfrentados plantea la necesidad de buscar soluciones a la división. Si bien éstas fueron por lo general traumáticas, el Edicto de Nantes marca un hito en la historia europea de la tolerancia. El llamado Edicto es en realidad un conjunto de tex- 
tos que establecen una serie de limitaciones no sólo al poder político establecido sino también al poder uniformizador del Estado que posteriormente la Revolución acentuará hasta límites extremos. La tolerancia del Edicto fue, sin embargo, en Francia poco digerida por una sociedad no preparada culturalmente a la diferencia cultural, religiosa o lingüística y que bebería entusiastamente de las fuentes del racionalismo uniformizador en cuanto la prudencia política dejara de ser estrictamente necesaria (Wanegffelen, 224) 2 .

e) 13 de diciembre de 1606: Estéfano Bocksay presenta en la Dieta de Hungría la Paz de Viena. En ocasiones se presenta esta Paz como el primer tratado internacional en el que se contiene una cláusula de protección de la libertad religiosa $\mathrm{y}$, por ende, de grupos minoritarios. Sin embargo, es confusa la naturaleza internacional del acuerdo. En cualquier caso, lo políticamente relevante del hecho es el reconocimiento de la tolerancia religiosa y del derecho a la diferencia. Bajo la hegemonía otomana fue relativamente factible el mantenimiento de esta tolerancia en Transilvania, pero derivó imposible con la llegada a Centroeuropa de nuevas realidades y teorías políticas. El principio de la tolerancia religiosa está en la base de la idea de derechos humanos individuales y puede ser considerado como el primer derecho realmente positivizado en este sentido. Las ideas de Locke respecto a los derechos individuales y a la limitación de poder que ellos suponen entroncan con tradiciones anteriores, entre las cuales, la de la tolerancia a la disidencia religiosa en una Europa ya claramente dividida, resulta una de las corrientes más importantes.

f) 11 de noviembre de 1620: Los Padres Peregrinos fundan la primera colonia en Nueva Inglaterra. El llamado Pacto de Myflower implica no sólo el establecimiento de una nueva comunidad de fe, sino igualmente la construcción de una nueva comunidad política. El posterior constitucionalismo norteamericano beberá en las fuentes de los padres fundadores y de su inspiración puritana. Por una parte, se trata de fundar una nueva comunidad política, que más tarde se reflejará en una declaración de independencia.

${ }^{2}$ La llegada de los Borbón al trono francés tiene también consecuencias para el País Vasco, puesto que supone la unión personal de los reinos de Navarra y Francia. A través de la Casa de Albret, principalmente representada por la madre de Enrique III, la reina de Navarra Juana de Albret, el influjo de la Reforma también se había extendido por la Vasconia continental, dando como fruto literario la primera traducción y edición del Nuevo Testamento en lengua vasca, realizada por Ioannes Leizarraga en 1571. 
Por otro lado, el acto del Myflower expresa hasta un punto una concepción en la que el poder político está basado en el consentimiento de los gobernados. Los peregrinos formarán a su vez una iglesia más democrática, si bien su gestión de la diferencia externa será terrible. El calvinismo predeterminista y la tradición veterotestamentaria del pueblo elegido llevaron a impulsar muy decididamente en ellos la idea de ser una comunidad escogida frente a las poblaciones indígenas y a justificar la aniquilación progresiva de ellas (Vidal, 301). También en este punto la tradición norteamericana será heredera de un sustrato semejante que no consiguió resolver jurídicamente hasta los años sesenta del siglo XX.

g) Octubre de 1685: El Duque de Prusia y elector de Brandenburgo acoge a los refugiados hugonotes. La revocación del Edicto de Nantes por Luis XIV supone la respuesta de una mentalidad absolutista a las diferencias internas y un precedente de la supuesta racionalización (Touchard, 281). Es relevante considerar la ausencia de una política positiva de la diferencia en el posterior constitucionalismo francés, en el que la premisa igualdad no sólo se extiende a la condición jurídica, sino también al imaginario nacional en su sentido más amplio. La acogida del Duque de Prusia a un buen número de exiliados hugonotes no está exclusivamente basada en criterios identitarios, pero viene a reflejar una disposición diferente a dicho respecto en el mundo cultural germano.

h) 15 de febrero de 1689: Los Comunes y los Lores presentan a Guillermo de Orange y María la Declaración de Derechos. La Revolución Gloriosa tiene también su lugar en el Muro de los Reformadores. Huelga resaltar la importancia de dicho acontecimiento en la tradición constitucional británica. Desde el punto de vista religioso, el acontecimiento supuso la consolidación definitiva de la Reforma en Inglaterra, tras un siglo y medio de incertidumbres. El hecho supone también el triunfo definitivo del Parlamento sobre el ejecutivo, pero sobre todo la limitación del poder a través de la consolidación de derechos individuales que más tarde estarían en la base nuestros modernos Estados de Derecho.

\section{Las bases del constitucionalismo moderno}

En la mayor parte de los países en los que resultó exitosa, la Reforma protestante se vio obligada a pactar o a transigir con el poder secular nacional. En el ámbito geográfico en el que se acabó imponiendo el luteranismo, la Reforma dio lugar a iglesias nacionales severamente 
controladas por los poderes seculares (Russell, 141), una disposición que venía ya produciéndose en el cristianismo oriental desde hacía siglos. Algo similar acabaría sucediendo en Inglaterra. Por el contrario, en los lugares en los que el calvinismo fue predominante, y siempre que el tamaño de la estructura política lo permitiera, la consecuencia de la Reforma fue la de la separación de Iglesia y Estado, pero desde la perspectiva de un poder secular al servicio del religioso, que en casos extremos, como el de Ginebra, acabó derivando en una teocracia (Chadwick, 82). En el espacio católico estas tendencias iban igualmente a reproducirse con otros ropajes ideológicos, siendo los jesuitas los que con mayor ahínco defendieron la separación de ambos poderes, identificándose en muchos lugares sus doctrinas con las de los propios calvinistas, frente a anglicanos, luteranos o galicanos (Sabine, 305).

Esta nueva situación de relación entre poder religioso y político se tradujo en el afianzamiento de las monarquías nacionales y de la forma política de Estado. El camino para la creación de los correspondientes Estados-nación quedaba así expedito, toda vez que el elemento religioso y las nuevas diferencias de culto se convertirían en los elementos más marcados de identidad, que sólo a partir del siglo XIX serían paulatinamente reemplazados en importancia por las diferencias de orden lingüístico (Petschen, 40).

El hecho de que la Reforma alentara estas circunstancias, creara un espacio europeo más plural y desarrollara nuevas ideas sobre la relación entre poder secular y poder temporal, ayudó a la aparición de diversas teorías políticas, entre las que encontramos la legitimación de los aspectos sustanciales del constitucionalismo moderno. Ahora bien, lo que realmente sienta las bases fácticas de ello, y motiva los acontecimientos que más arriba hemos relatado, no es tanto la propia Reforma en sí, sino las consecuencias de la misma, sin que puedan identificarse todas las ideas políticas que alumbrarían el Estado de Derecho con aquel movimiento, sino con el entorno propicio que el éxito de aquél movimiento provocó en los siglos XVII y XVIII. En aquellas zonas del continente en las que no aparecieron cambios relacionados con la pluralidad religiosa provocada por la Reforma, el desarrollo significativo de ideas políticas modernas quedó estancado hasta muy entrado el siglo XIX. Así sucedió, por ejemplo, en ámbitos como el de la Península Ibérica, los Balcanes o la Europa oriental.

En consonancia con todo ello, podemos resaltar que los acontecimientos que más arriba se han descrito como hitos fundamentales de la Reforma, condensan en mayor o menor medida la formulación de ideas políticas novedosas que sirven de base a las tradiciones constitucionales que suelen ser objeto de estudio en nuestras facultades o en nuestros 
manuales de Derecho político. De las tres grandes tradiciones constitucionales que suelen servirnos de referencia, esto es, la británica, la norteamericana y la francesa, son las dos primeras las que mejor se ven reflejadas en este marco histórico político. Ya hemos señalado cómo la tradición constitucional francesa engarza con elementos que difieren del sustrato de la Reforma, en particular, el tema de la diferencia. Sin embargo, ello no deja de reflejarse también en el Muro ya que, como señalamos anteriormente, la adopción y posterior revocación de los edictos de Nantes marcan también una trayectoria previa al desarrollo constitucional francés establecido sobre bases sociológicas y religiosas diferentes a las de las islas británicas o las del nuevo mundo. Es posible, por el contrario, que podamos identificar más elementos de conexión con la tradición constitucional suiza, si bien ello resulta sin duda más complejo por el peculiar sistema jurídico-político de la Confederación Helvética.

Del pedagógico recorrido histórico y religioso del Muro, derivan fundamentalmente cuatro ideas fuerza que nos interesan desde el análisis del surgimiento del movimiento constitucionalista. En efecto, el cuerpo de enseñanzas políticas que derivarían de los acontecimientos narrados en el monumento religioso, podría condensarse en torno a cuatro temas que van a marcar los posteriores desarrollos constitucionales:

\section{a) La idea de la tolerancia frente a la diversidad religiosa}

No parece que la idea de la tolerancia pueda inferirse directamente de las propias enseñanzas de los principales reformadores, quizás con la excepción del Lutero anterior a 1525 (Wanegffelen, 71), pero sí es cierto que sus ideas dieron lugar a una mayor comprensión respecto a la disidencia religiosa (Touchard, 214-219). La exaltación de la conciencia como última razón imperativa y la insistencia en eliminar la función mediática para llegar a la fe, procurando que cada cristiano lo hiciera directamente a través de la lectura de los libros sagrados, tuvo mucha importancia en el desarrollo de la modernidad. La Reforma, al anular el peso de la Tradición y concentrarse en el de la Literatura como fuente de la Revelación, ayudó a consolidar el sujeto activo característico de la modernidad, como lo hicieron el racionalismo cartesiano y el paulatino desarrollo de las ciencias, inspirando una visión más antropocéntrica que teocéntrica de la realidad. Sin quererlo, los reformadores están abriendo la puerta al pluralismo y a la secularización de la sociedad, los dos máximos exponentes del paso de la misma a la modernidad (Velasco, 69-70).

La tolerancia frente a la divergencia o disidencia religiosa no fue, con mucho, la pauta común de actuación ni de argumentación en los si- 
glos XVI y XVII. Antes al contrario, las separaciones religiosas, a diferencia de las lingüísticas, provocaron amargas controversias y nuevas identidades con una fuerte capacidad movilizadora, tendente a la autodefensa, cuando no a la eliminación de la alteridad (Petschen, 41). Ello se extendió también, como resulta lógico, a quienes no profesan ningún culto cristiano, como los indios de América, y sentó las bases para las justificaciones no sólo de nacionalismos agresivos, sino de imperialismos posteriores, racismos y fundamentalismos excluyentes, más o menos fundamentados en ideas de Destino manifiesto o de elección natural o divina (Vidal, 300). No en vano, en torno al reconocimiento de las sociedades aborígenes del Nuevo Mundo gira otro debate paralelo que nos lleva al mismo tema del respeto por la diferencia, con consecuencias similares en la práctica en los ámbitos católico y protestante.

Sin embargo, es cierto al mismo tiempo que importantes reformadores defendieron con coherencia el principio de la tolerancia. El ejemplo más adecuado en este sentido es, desde luego, el de Roger Williams (Babel, 39), aunque otras figuras históricas representadas en el Muro pasen por ser también defensores de la idea de la tolerancia religiosa. Este concepto, teóricamente tan ligado al calvinismo, se tradujo en criterio político allá donde se pudo comprender que no había otra forma más rentable de solucionar las diferencias religiosas que incorporándolas a la estructura institucional del respectivo país. Son claros en este sentido los ejemplos del Edicto de Nantes en Francia (Carvalho, 22) y de la Paz de Viena para Transilvania, pero todo hace pensar que fue más la necesidad que la convicción lo que permitió que se concretara la sugestiva idea de la tolerancia (Wanegffelen, 53). En efecto, como puede leerse en el mismo Muro, Enrique IV sanciona la aprobación de los edictos con estas palabras:

«Ahora que Dios ha tenido a bien permitirnos disfrutar de un mejor sosiego, hemos estimado que no podríamos emplearlo mejor que ocupándolo en aquello que puede concernir la gloria de su santo nombre y servicio, y en procurar que él pueda ser adorado y rezado por todos nuestros súbditos. Y si no ha tenido a bien permitir que así sea todavía a través de una misma forma y religión, que lo sea al menos con una misma intención» ${ }^{3}$.

\footnotetext{
${ }^{3}$ Hemos traducido libremente el texto en francés de la época que obra en el Muro y que reza de la siguiente manera: «Maintenant qu'il plaît à Dieu commencer à nous faire jouir de quelque meilleur repos, nous avons estimé ne le pouvoir mieux employer qu'à vacquer à ce qui peut concerner la gloire de son sainct nom et service et à pourvoir qu'il puisse être adoré et prié par tous nos subjects. Et s'il ne lui a plu permettre qu'il que ce soit pour encore en une même forme et religion, que ce soit au moins d'une même intention».
} 
El texto no deja de reflejar una cierta resignación frente a la falta de unidad de culto y busca el argumento que permita reubicar ambas profesiones de fe en torno a una misma lógica (la intención) que deslegitime la represión recíproca de ambos grupos. Ni qué decir tiene que esta tolerancia para con la poderosa minoría hugonote no se extendía a miembros de otras religiones, ni siquiera a otros grupos cristianos disidentes. En una línea parecida puede recordarse que el mismo Locke, que defendía la tolerancia como principio, justificaba no poder admitirla frente a miembros de otras religiones con otra suerte de argumento, ni tampoco para los católicos, pese a ser cristianos, precisamente por el poco religioso argumento de que obedecían a una autoridad política ajena a la del Estado. En este caso, la tolerancia religiosa cede ante la consolidación del Estado como forma política ideal (Botella, 200).

En el caso de Hungría, la aceptación de tolerancia en la Paz de Viena está redactada en términos más jurídicos y garantistas. Por ello pasa por ser un primer instrumento jurídico de protección de la libertad religiosa, que se adelanta en casi medio siglo a los posteriores desarrollos jurídicos internacionales (Ruiz, 24). El extracto del tratado que podemos observar en el Muro señala:

«Su majestad Imperial y Real nunca molestará o permitirá a otros que molesten a ningún estamento u orden del reino en su religión o confesión. El libre ejercicio de culto religioso es garantizado a todos... Las funciones públicas del reino serán conferidas en Hungría y sus territorios asociados a aquellos que lo merezcan, sin discriminación ninguna basada en la creencia religiosa...» ${ }^{4}$.

En esta línea, la tolerancia religiosa como idea, en parte defendida por los reformadores, fue inspirando a la larga, por un lado, una aceptación de la diversidad característica de las sociedades modernas y, por otro, un reconocimiento de la esfera individual de libertad de todo individuo. La libertad de religión es, quizás el primero de los derechos humanos reconocido jurídicamente con carácter general y abre la puerta a la existencia de derechos naturales previos a la constitución de cualquier poder político. Por vez primera debe admitirse que las comunidades políticas no se modelan a imagen y semejanza de su soberano y, en consecuencia, se abre la posibilidad también de un cuestionamiento de la sede en la que se reside dicha soberanía. La contribución de Bodino

${ }^{4}$ Este texto figura en el Muro en latín, lengua original del tratado. A nuestros efectos, hemos hecho una traducción a lengua castellana cotejando al mismo tiempo las versiones inglesa y francesa que figuran en Higman, 24. 
en este sentido es muy relevante y plenamente coherente con la situación descrita, pero la propia idea de tolerancia cristalizó de modos diversos en las diferentes sociedades, en función de las circunstancias de mayoría o minoría en las que cada grupo se veía forzado a vivir. Esto explica una tradición liberal común de respeto a la autonomía individual en las diferentes tradiciones constitucionales europeas, pero también posiciones muy diferentes en torno a la aceptación de la discriminación positiva respecto a los grupos cultural, religiosa o lingüísticamente minoritarios.

\section{b) La idea de la necesidad de limitar el poder temporal}

Las doctrinas protestantes, particularmente las de inspiración calvinista, ayudaron a cambiar la percepción que en determinadas sociedades se tenía de aspectos tan fundamentales para la vida social como el trabajo, el progreso social o la necesidad de organización comunitaria. Respecto al primer caso, si para el cristianismo tradicional el trabajo se entendía como una suerte de castigo divino con el que ganarse un sustento, con el calvinismo, el trabajo se transforma en el medio a través del cual Dios permite al hombre transformar el mundo. Por su parte, el estado de pobreza que para la visión tradicional venía a ser considerado como una condición querida por Dios, tras la doctrina calvinista se convierte en una auténtica desgracia y señal de predestinación negativa (Vidal, 288).

Del mismo modo, el calvinismo esconde una desconfianza radical hacia la naturaleza humana, dañada por la Caída, que no puede por menos de extenderse a todas sus realizaciones, entre las que se halla desde luego la organización política. Esta perspectiva ayudó al cuestionamiento de las autoridades tradicionales y a la consecuencia lógica de buscar límites respecto a un poder que en todo caos no puede estar sino al servicio de la Iglesia. La radical separación entre Iglesia y poder temporal que Calvino defiende se convierte en determinadas circunstancias en sometimiento total de éste a aquélla, al contrario de lo que ocurriría en el ámbito luterano. En todo caso, lo relevante en este punto es subrayar la generación de desconfianza frente al poder político, lo que supone una formidable base de partida para las teorías que buscan la limitación y debilitamiento del mismo, en parte, porque debe asegurarse la tolerancia religiosa anteriormente mencionada y otros derechos individuales.

En este sentido, la formulación del Bill of Rights de 1689 que nos presenta el Muro es contundente al limitar las prerrogativas regias y establecer un nuevo sistema constitucional de mayor equilibrio interno: 
«Los Lores espirituales y temporales, y los Comunes, encontrándose reunidos en una representación libre y plena de esta nación, para la reivindicación y la defensa de sus tradicionales derechos y libertades, declaran: que el pretendido poder de suspender leyes por la autoridad real sin el consentimiento del Parlamento es ilegal... que percibir un impuesto sin el asentimiento del Parlamento es ilegal... que la elección de los miembros del Parlamento debe ser libre» ${ }^{5}$.

La limitación, en consecuencia, se hace con base en unos derechos y libertades previos, que a su vez son garantizados por la acción de los representantes populares reunidos en un Parlamento. Este será en lo sucesivo el órgano que dirá la última palabra en la organización constitucional británica. En alguna medida esta nueva realidad política tiene su legitimación en una desconfianza respecto de los poderes temporales, particularmente los ejecutivos, que permanecerá viva en la tradición anglosajona. A diferencia de ésta, la tradición francesa se expresará de modo bien distinto cuando un siglo más tarde estalle la Revolución.

El reforzamiento de las instituciones representativas o cuasiparlamentarias que se deriva de la necesidad de controlar el poder ejecutivo, se expresa igualmente en el mensaje que Guillermo el Taciturno dirige a los Estados Generales y que el Muro refleja parcialmente:

«Asumamos juntos la defensa de este buen pueblo. Espero, con vuestra ayuda y por la gracia de Dios, que he sentido tantas veces en el pasado y en asuntos tan complejos... que lo que sea resuelto por vosotros, yo lo mantendré» 6 .

\section{c) La idea de que el gobierno se fundamenta en el consentimiento de los gobernados}

Las dos citas históricas del Monumento incorporadas en el apartado anterior son también ejemplos indirectos de la idea de que el gobierno se fundamenta en el consentimiento de los gobernados. Así se infiere

${ }^{5}$ El texto se encuentra en el inglés original en el propio Muro, con el siguiente tenor: "The Lords spirituall and temporall and Commons being now assembled in a full and free representative of this nation doe for the vindicating and asserting their auntient rights and liberties declare: That the pretended power of suspending of laws by regall authority without consent of Parlyament is illegall... That levying money without grant of Parlyament is illegall... That election of Members of Parlyament ought to be free». La traducción es nuestra.

${ }^{6}$ Este texto figura en el Muro en neerlandés. A nuestros efectos, hemos hecho una traducción a lengua castellana cotejando al mismo tiempo las versiones inglesa y francesa que figuran en Higman, 15. 
del poder decisorio que en ambas ocasiones se reconoce al órgano que en mayor o menor medida representa al pueblo.

Este principio evoluciona también en paralelo a la creación de nuevas iglesias reformadas, cuando éstas se hallaban en situación de minoría frente a una sociedad mayoritariamente católica (caso de los hugonotes franceses) o bien cuando se encuentran con un poder político hostil y mientras no consigan imponerse. Este segundo sería durante un tiempo el caso de Escocia o de los Países Bajos. Respecto a estos últimos, la Declaración de Independencia de 1581 anteriormente aludida señala, como se recoge textualmente en el propio Monumento, que:

«Los súbditos no son creados por Dios para el Príncipe en orden a obedecerle en todo lo que pueda satisfacerle mandar, sea por Dios o contra Dios, razonable o irrazonable, y para servirle como esclavos. Bien al contrario, el Príncipe es creado para sus súbditos (sin los cuales no puede ser Príncipe) para gobernarlos según el Derecho y la razón» ${ }^{7}$.

La primacía corresponde, por lo tanto, a los súbditos, de los que en última instancia irradia todo poder. En el siglo posterior a esta formulación política aparecerían las teorías más sólidas del Contrato Social, que fueron facilitadas por algunas teorías políticas y eclesiológicas protestantes (Johnston, 143). La idea de covenant juega aquí un papel singular que reaparecerá en la tradición constitucional norteamericana. De alguna forma se recogen de nuevo las tradiciones germanas de creación del Derecho, acalladas y sometidas durante siglos por la tradición de inspiración romana.

El tema aquí planteado del necesario consentimiento de los gobernados para hacer legítimo el poder temporal, tiene a su vez una derivación importantísima en la discusión sobre el derecho de resistencia. Ni Lutero ni Calvino fueron defensores de dicho derecho y por lo general abominaban de los actos de resistencia, prefiriendo la tiranía a la anarquía (Johnston, 162). Ahora bien, Calvino no era tanto partidario de la monarquía cuanto de la aristocracia como forma ideal de gobierno y en alguna medida legitima una cierta capacidad de resistencia que no se atribuye a todos los súbditos sino solamente a determinados magistrados (Sabine, 290). Si posteriormente escritores calvinistas justificaron el derecho de resistencia, no lo hicieron por coherencia con las enseñanzas

${ }^{7}$ Este texto figura en el Muro en neerlandés. A nuestros efectos, hemos hecho una traducción a lengua castellana cotejando al mismo tiempo las versiones inglesa y francesa que figuran en Higman, 15. 
del gran reformador, sino en virtud de las particulares circunstancias políticas en las que se vieron inmersos. Tampoco puede olvidarse en este sentido la justificación del derecho de resistencia por parte de una escuela de religiosos jesuitas (Sabine, 305). Ambas corrientes, por motivos y con objetivos distintos, debían chocar con la justificación divina del poder de los reyes y ayudaban a minar los cimientos de las inminentes experiencias absolutistas.

\section{d) La idea de la constitución de nuevas comunidades políticas}

La misma doctrina del derecho de resistencia que se desarrolló en una segunda fase de propagación de la Reforma, condujo a la aceptación como lógica de otra importancia consecuencia política, a saber, la posibilidad del establecimiento legítimo de nuevas comunidades por segregación de los espacios ya existentes. A esta misma conclusión ayudó igualmente la idea de que el poder político descansa sobre el consentimiento de los gobernados y, por tanto, que aquél es alterable, cuando desaparece éste.

Así, por un lado se tiende a justificar la independencia de una determinada comunidad como una suerte de rebelión contra la tiranía de un monarca (inglés en el caso norteamericano, español en el caso neerlandés), pero al mismo tiempo se está legitimando la posibilidad de crear nuevas comunidades políticas si media un pacto fundacional para ello en el que participan los futuros gobernados. En última instancia se reconoce que la segregación o agregación de territorios de espacios políticos ya conformados debe hacerse con el consentimiento de la población allí residente. A través de una suerte de covenant, se crean nuevas formas políticas, cuya legitimidad no puede ponerse en duda, en la medida en que establecen sus propias fuentes normativas:

«En el nombre de Dios, amen. Nosotros, los abajo solemnemente firmantes, nos reunimos mutuamente por el presente pacto, delante de Dios y en presencia los unos de los otros, en un cuerpo civil y político para legislar y establecer aquellas leyes justas e iguales que se juzgará oportuno y conveniente para el bien general de la colonia» ${ }^{8}$.

8 El texto original del Muro se encuentra en el ingles de la época: «In the name of God, Amen. We... doe by these presents solemnly and mutually in the presence of God and one of another covenant and combine ourselves togeather into a civill body politick,... and by vertue hearof to enacte, constitute and frame such just and equall lawes... as shall be thought most meete and convenient for the generall good of the colonie.» La traducción es nuestra. 
Como puede observarse en el texto, que corresponde al relieve del Muro representativo del Pacto del Myflower, los padres peregrinos no sólo se organizan como comunidad de fe sino que explícitamente constituyen un cuerpo cívico y político que se arroga potestad para legislar y organizar leyes justas e iguales. Se trata de una auténtica fundación constitucional que servirá de inspiración al posterior proceso de independencia norteamericano.

La misma experiencia histórica había sido ya vivida por los Países Bajos y sirvió temporalmente en otros países mientras el calvinismo se encontraba en minoría o en confrontación con un poder político vecino más importante. Este sería el caso de Escocia, Navarra o Transilvania durante parte del siglo XVI. Como ya hemos señalado con anterioridad, la Reforma anuncia claros elementos nacionalistas (Hernández, 215). En cualquier caso, se va construyendo también una legitimación política de los procesos de secesión sobre la base del gobierno consentido y del derecho de resistencia frente a la tiranía. Ello provocaría consecuencias políticas de primera importancia cuando las características nacionales sustituyan a las religiosas como fuente primordial de la identidad colectiva.

\section{Conclusión}

A través del análisis de algunos de los elementos del Muro de los Reformadores hemos podido ir dibujando una serie de trazos que conforman un cuadro de implicaciones complejas entre la Reforma y las principales tradiciones constitucionales de nuestro entorno cultural. $\mathrm{Ni}$ el estudio de los datos que el propio Monumento nos ofrece está agotado ni, mucho menos aún, el cuadro de acontecimientos políticamente relevantes de aquella época queda completado. Antes al contrario, es tiempo de relativizar el impacto de las nuevas realidades religiosas de la Edad Moderna, teniendo en cuenta que todos estos procesos aquí descritos se producen en un contexto sobre el que actúan también otros factores de no poca importancia. Entre éstos, son destacables fenómenos tan singulares como los siguientes:

a) El desarrollo del Humanismo, que precedió a la Reforma y supuso impulsar unas nuevas bases culturales en parte de la Europa occidental.

b) El llamado descubrimiento de América, que confrontó a los europeos con la existencia de nuevas realidades geográficas y antropológicas y con dilemas en relación con el gobierno de las mismas. 
c) El florecimiento económico, especialmente en Italia, Alemania y los Países Bajos, unido al desarrollo del capitalismo. Las conexiones entre capitalismo y calvinismo son desde luego sugerentes, puesto que la ética propugnada por Calvino responde bien a los intereses de la clase burguesa. Sin embargo, no puede olvidarse que el capitalismo se implantó en determinadas regiones de Europa con anterioridad a la Reforma y que se desarrolló igualmente en zonas en las que ésta no tuvo éxito.

d) El desarrollo tecnológico, que permitió asimilar nuevos conceptos y realidades, que a su vez pondrían en cuestión determinados dogmas tradicionales e incluso la posición de la persona en el universo.

e) Dentro de los progresos tecnológicos, requiere un lugar particular la generalización de la imprenta, creada en el siglo XV, que permitiría en los siglos posteriores una rapidez en la difusión de las ideas desconocida hasta entonces. Este hecho va unido también a un aumento significativo del número de personas alfabetizadas y al desarrollo y afianzamiento de una serie de lenguas nacionales que dividirían el espacio cultural europeo-occidental, hasta entonces unificado en torno al latín.

f) La consolidación del Estado y de las monarquías nacionales como los espacios políticos de referencia de cara a la modernidad.

En definitiva, la Reforma y su éxito pueden ser considerados causa y consecuencia al mismo tiempo de muchos de los factores que interactúan para poner las bases del constitucionalismo moderno. En todo caso, hemos mantenido que, si bien la propia Reforma aportará elementos importantes de modernización de la política, es más definitiva en este sentido la situación de diversidad religiosa que plantea su extensión. Es esta diversidad y las diferentes circunstancias en las que se produce, lo que estimula la confrontación política también en clave ideológica. Los juegos de mayorías y minorías, las relaciones entre poderes políticos y religiosos o las confrontaciones entre unos poderes temporales y otros, crean un nuevo espacio privilegiado para el desarrollo de teorías y prácticas modernizantes, no todas ellas estrictamente novedosas, pero sí planteadas en un contexto históricamente más propicio que cualquier otro anterior. Más que un mérito atribuible a la Reforma, las bases del constitucionalismo moderno, al menos en algunos de los países de nuestro entorno, se vieron favorecidas por la situación fáctica derivada de las luchas religiosas del siglo XVI y de la confluencia de otros factores sociales, culturales y políticos, como los más arriba mencionados. 
Como señalábamos más arriba, esto puede quedar demostrado por el hecho de que en las zonas del continente europeo en las que no se produjeron cambios profundos relacionados con la pluralidad religiosa provocada por la Reforma, o en las que la nueva diversidad religiosa no perduró sólidamente más allá de una generación por la reacción contrarreformista, la evolución de las teorías políticas permaneció llamativamente estancada. Con tímidas excepciones, tampoco hay en dichos espacios acontecimientos políticos prácticos durante la Edad Moderna que resulten especialmente significativos a este respecto. Es el caso de zonas como la Península Ibérica, la Europa oriental eslava y los Balcanes, sometidos en su casi totalidad al Imperio Otomano a lo largo de todo este período. España y Portugal permanecieron masivamente fieles a la fe católica, con un grado de disidencia muy reducido. Por su parte, la Europa oriental y la península balcánica, en su mayor parte se mantendrían bajo el influjo de las iglesias ortodoxas. La primera, bajo el dominio espiritual de la Tercera Roma, Moscú, cuyo patriarcado o sínodo extendían su influencia en paralelo al formidable proceso de expansión ruso. Los Balcanes, bajo soberanía otomana, albergaban algunas poblaciones sometidas a Roma (básicamente Hungría y Croacia hasta la Paz de Passarowitz en 1699), junto a una mayoría social que dependería eclesiástica y espiritualmente del Patriarca Ecuménico de Constantinopla hasta el siglo XIX.

En este sentido, la Reforma ahondó la división político-cultural del continente europeo y marcó el ámbito geográfico que ejercería el liderazgo intelectual en el continente durante los siguientes siglos. Las tradiciones constitucionales originarias, británica, norteamericana, francesa y helvética, vienen a insertarse en mayor o menor medida en dicho substrato político. Posteriormente, este liderazgo intelectual vendría a corresponderse cada vez más claramente con el liderazgo militar y económico y, tras ser ejercido desde Europa durante aproximadamente dos siglos, saltaría el Atlántico para consolidarse hasta nuestros días en aquel espacio que se empezaba a alumbrar cuando los peregrinos del Myflower suscribían su pacto fundacional.

En definitiva, el Monumento Internacional de la Reforma de Ginebra nos ofrece un incomparable marco pedagógico para sintetizar y relacionar al mismo tiempo elementos muy significativos de las tradiciones constitucionales vigentes hoy en Occidente. No en vano, la interacción entre política, religión, historia y cultura es el marco conceptual y fáctico en el que se incardina cualquier Derecho positivo y particularmente un Derecho constitucional. Un recorrido visual e imaginario por los acontecimientos que resalta artísticamente el Muro, e incluso por las biografías de los personajes allí representados, podría 
traducirse en una sugerente y eficaz lección introductoria de Derecho constitucional.

En una época en la que el estudio del Derecho se orienta básica o mayoritariamente al análisis de un ordenamiento jurídico vigente, la parcela que representa el Derecho constitucional debe reclamar con mayor insistencia la conveniencia de enfoques pluridisciplinares, en los que puedan combinarse aproximaciones contextuales mucho más complejas que las derivadas de perspectivas exclusivamente técnicas. Al fin y al cabo, mucho de los problemas del Derecho Constitucional son más cuestiones de la teoría política a las que debe proveerse posteriormente del adecuado ropaje jurídico, que asuntos de mera técnica jurídica sobre aspectos políticos. En fin, las sociedades desarrolladas actuales, cada vez más plurales en cuanto a los miembros que las integran, reclaman con fuerza creciente la necesidad de redefinir dinámicamente las bases de la convivencia política. Y esta adaptación progresiva de los fundamentos jurídico-políticos de nuestras comunidades institucionales sólo será viable desde la comprensión compleja y completa de las distintas tradiciones políticas, culturales y religiosas que se integran en ellas.

\section{Bibliografía}

Babel, H. et alia (1985), Des Hommes, Une idée: la Réforme, Fondation des clefs de Saint-Pierre, Ginebra.

Botella, J.; Cañeque, C. y Gonzalo, E. (eds.) (1994), El Pensamiento Político en sus Textos. De Platón a Marx, Tecnos, Madrid.

Cañellas, J.N. (2000), Las Iglesias Apostólicas de Oriente; Historia y Características, Ciudad Nueva, Madrid.

Carvalho, B. (2001), «Keeping the State: Religious Toleration in Early Modern France and the Role of the State in Minority Conflicts», en European Yearbook of Minority Issues, volume n 1, 2001/2, pp. 5-27.

Chadwick, O. (1979), The Reformation (The Pelican History of the Church 3), Penguin Books, Middlesex.

Green, V. (1998), The European Reformation, Sutton Publishing, Gloucester.

HERnÁNDEZ BECERRA, A. (1997), Las Ideas políticas en la Historia, Universidad Externado de Colombia, Bogotá.

Higman, F. (1993), Monument International de la Réformation, Genève, Fondation des clefs de Saint-Pierre, Ginebra.

Johnston, P. y SCRIBner, B. (1998), La Reforma en Alemania y Suiza, Akal, Madrid.

Ladero Quesada; M.A. (2002), Espacios del hombre medieval, Arco-Libros, Madrid.

McClelland, J.S. (1996), A History of Western Political Thought, Routledge, Londres. 
Meyendorff, J. (2002), Saint Grégorie Palamas et la mystique orthodoxe, 2. ${ }^{a}$ ed., Éditions du seuil, Paris.

Mitre Fernández, E. (2000), Las herejías medievales de Oriente y Occidente, Arco-libros, Madrid.

Morrow, J. (1998), History of Political Thought. A Thematic Introduction, Mcmillan Press Limited, Londres.

PARRY, K. et alia (eds.) (1999), The Blackwell Dictionary of Eastern Christianity, Blackwell publishers, Oxford.

PetSCHEN VerdagueR, S. (1990), Las minorías lingüísticas de Europa Occidental: Documentos (1492-1989), Parlamento Vasco, Vitoria-Gasteiz.

RuIZ VIEYTEZ, E.J. (1998), La protección jurídica de las minorías en la Historia Europea, Universidad de Deusto, Bilbao.

Russell, B. (1995), Historia de la Filosofía Occidental, 6. ${ }^{a}$ ed., Austral, Madrid.

Sabine, G.H. (1995), Historia de la Teoría Política, 3. ${ }^{a}$ ed., Fondo de Cultura Económica, México.

Touchard, J. (1998), Historia de las Ideas Políticas, $6 .^{a}$ ed., Tecnos, Madrid.

VÁzQuez Borau, J.L. (2003), Las Iglesias Cristianas (Católica, Ortodoxa, Protestante y Anglicana), San Pablo, Madrid.

Velasco Criado, D. (2001), Pensamiento Político Contemporáneo, 2. a ed., Universidad de Deusto, Bilbao.

VIDAL, C. (1998), Los textos que cambiaron la historia, Planeta, Madrid.

WANEGFFELEN, T. (1998), L'Édit de Nantes. Une histoire Européenne de la tolérance (XVIe-XXe siècle), Librairie Générale Française, Paris. 